\title{
Comparison of the results of asbestos fibre dust counts in lung tissue obtained by analytical electron microscopy and light microscopy
}

\author{
FD POOLEY, DL RANSON \\ From the Department of Mineral Exploitation, University College, Cardiff
}

SUMmARY The efficiency of the light microscope with that of the electron microscope in detecting asbestos fibres in human lung tissue was computed. Necropsy material from 55 patients who had died from asbestos related diseases was analysed independently by phase contrast microscopy and electron microscopy. As expected the number of fibres identified using electron microscopy was higher than that identified by light microscopy. By adjusting the electron microscope fibre counts to allow for the limited resolving power of the light microscope, however, a significant correlation of the number of fibres identified using the two methods was obtained. The best correlation was found with specimens containing crocidolite (correlation coefficient $\mathbf{0} \cdot 79$ ) and amosite (correlation coefficient $\mathbf{0} \cdot \mathbf{7 4}$ ), while chrysotile gave a much lower correlation (correlation coefficient $0 \cdot 15$ ). The cumulated fibre diameter distribution obtained using the electron microscope suggests that the light microscope is able to visualise only $5 \%$ of crocidolite, $26.5 \%$ of amosite, and $0 \cdot 14 \%$ of chrysotile present in lung tissue. Therefore, although it is possible, using the electron microscope, to predict the asbestos fibre count that would be obtained by light microscopy, the reverse prediction cannot be made: it is impossible to determine the proportion of the various asbestos mineral types using the light microscope.

In recent years an important aspect in the study of diseases induced by asbestos has been the type of fibre and the amount of exposure that may result in pathological changes. ${ }^{1}$ Considerable progress has been made in this field since the development of techniques that enable single asbestos fibres in human tissues to be identified using electron microscopy and electron microprobe analysis. ${ }^{2-5}$

Light microscope studies have been made on lung tissue to assess secular trends in ferruginous body concentrations over a period of time with the aim of establishing the proportion of people in different cities and towns in whom ferruginous bodies can be found. ${ }^{6}$ Other studies have been performed to determine whether there is a relation between the concentrations of fibrous particles and ferruginous bodies detected in the lungs and different diseases. ${ }^{7-9}$ These studies, using the light microscope, were all performed assuming that the ferruginous bodies observed were all formed on asbestos mineral fibres and that the uncoated fibres observed were also asbestos, although it is well known that they cannot be identified using an optical microscope.

Accepted for publication 20 November 1985
The electron microscope and microprobe techniques provide the most accurate and detailed information on the identification of asbestos mineral and other fibres, but this equipment is very expensive and is only available in a limited number of research centres. This investigation was undertaken to test the efficiency of the light microscope in detecting asbestos particles in lung tissue, and in particular, to compare counts obtained by light microscopy with those obtained by analytical electron microscopy to determine whether or not there was any relation between the observations obtained by the two techniques.

The samples of lung tissue examined were taken from necropsy material from patients who had mainly died from asbestos related disease, the remainder was taken from patients who had died from cardiovascular disease or bronchial carcinoma. The objective in the selection was to obtain a set of tissue samples with as wide a range of asbestos fibre contents as possible. The specimens of tissue used in the optical microscopic investigation were all taken from the lower lobes of the lung and were prepared and examined in the department of pathology, City Hospital, Nottingham by one of the authors. The specimens of tissue used in the electron microscopic studies 
were taken from the upper and lower lobes of the lung, and the composite sample was prepared and examined in the department of mineral exploitation by the other author.

In some cases the number of asbestos fibres in the lung can vary by as much as $50 \%$ using electron microscopic counts. It is not known, however, whether this variation is dependent upon the type or severity of exposure to asbestos. Normally, whole lungs are not available for quantitative determinations of asbestos content. However, as the differences between light and electron microscopic counts were expected to be much larger than the possible fibre concentration differences throughout the lung, it was not considered necessary to examine specimens from the same area by both techniques.

Necropsy material from 55 patients was examined, although 59 sets of results were recorded as four specimens were re-examined by optical microscopy for a second evaluation of fibre number concentration. (Table 2, specimen numbers $23 / 40,26 / 41$, $27 / 42$, and $36 / 43$ ).

Necropsy material, although originating from the same patients, was therefore examined by independent laboratories using different specimen preparation techniques and microscopic equipment.

\section{Material and methods}

The light microscope counts of fibre concentrations were made using the method of Ashcroft and Hepplestone: ${ }^{10}$ this entails the potassium hydroxide digestion of lung tissue. The fibres were counted using a modified Fuchs Rosenthal counting chamber and viewed with a phase contrast microscope. Both naked fibres and ferruginous bodies were counted, even though sometimes a fibre could not be discerned in association with the body. The optical cont was calculated and expressed as the number of fibres/g of dried lung tissue. The procedure used in the preparation of the tissue specimens consisted of first dissecting two cubes of lung tissue $1-1.5 \mathrm{~cm}^{3}$ from each specimen, avoiding the pleura, large bronchi, and blood vessels. Both cubes were weighed and one of the cubes was dried for 24 hours in an oven at $60^{\circ} \mathrm{C}$. The other cube of tissue digested in $40 \%$ potassium hydroxide at $100^{\circ} \mathrm{C}$ for two hours. The resulting residue was then concentrated by centrifugation and the supernatant removed leaving $0.5-1.0 \mathrm{ml}$ of solution above the deposit in the centrifuge tube. The residue was then resuspended in filtered distilled water and the resulting suspension used to fill a modified Fuchs Rosenthal counting chamber. Using an optical microscope in a phase contrast mode the fibres in the chambers were counted until three consistent readings were obtained. Using the wet weight of both cubes of lung and the weight of the cube that had been dried, the weight of the cube digested was calculated. The fibre concentration of the tissue on a dry weight basis was then computed from the number of fibres counted per unit volume of the residue suspension placed in the counting chamber.

The electron microscopic counts of fibre concentrations were performed using a procedure outlined by Pooley and Clark. ${ }^{5}$ The specimens of lung tissue were prepared by initial potassium hydroxide digestion of tissue that had been dried to a constant weight at $80^{\circ} \mathrm{C}$. The dust extracted from the tissue samples was filtered onto $0.2 \mu \mathrm{m}$ nuclepore filters, which were then carbon coated when dry. The dust from a specific weight of tissue was thus deposited on a known area of filter. Sections of the filter, bearing the extracted dust embedded in a carbon film, were then prepared for electron microscopy by dissolving away the nuclepore filter using chloroform, leaving the carbon film. The dust deposit was then mounted on gold electron microscopic support grids. The electron microscope filter preparations were examined at a magnification of $20000 \mathrm{x}$ and scanned to detect fibres in a regular manner. Each fibre was analysed using an energy dispersive $x$-ray analysis system and identified. Detecting and analysing fibres in this way established the number of each fibre type present. The dimensions of each fibre were also noted so that size distribution for each type could be obtained: both the diameter and length of each fibre were recorded. The number of fibres/unit area of the electron microscope preparation was determined either directly from the microscope by counting fibres in a given area, or from the subsequent examination of electron micrographs of random areas of the preparations. These fibre counts were then used to obtain the fibre concentration on the original filter specimen, which contained the dust extracted from a known quantity of tissue: in this way fibre concentrations/g of dried tissue were calculated.

The total mineral fibre counts obtained from the analytical electron microscope were therefore reduced to obtain the number of asbestos mineral fibres and also non-asbestos fibres present/unit of tissue.

\section{Results}

Tables 1, 2, and 3 list the results of total electron microscopic mineral fibre counts and the abstracted total asbestos fibre counts for each of the specimens together with the corresponding optical microscopic counts. Table 1 shows the results from those specimens, in which the predominant asbestos mineral detected by electron microscopy in the lung was crocidolite; Table 2 shows the results from those lungs in which amosite was the predominant asbestos mineral. Table 3 shows the results from those lungs in which chrysotile was the principal asbestos mineral detected. 
Table 1 Asbestos and other fibrous particle counts obtained from lung tissue specimens containing crocidolite as predominant asbestos mineral*

\begin{tabular}{|c|c|c|c|c|}
\hline $\begin{array}{l}\text { Specimen } \\
\text { No }\end{array}$ & $\begin{array}{l}\text { Optical microscope counts } \\
\times 10^{6}\end{array}$ & $\begin{array}{l}\text { Electron microscopic adjusted } \\
\text { counts } \times 10^{6}\end{array}$ & $\begin{array}{l}\text { Total electron microscopic } \\
\text { asbestos fibre counts } \times 10^{6}\end{array}$ & $\begin{array}{l}\text { Total electron } \\
\text { microscopic mineral } \\
\text { fibre counts } \times 10^{6}\end{array}$ \\
\hline $\begin{array}{l}1 \\
2 \\
3 \\
4 \\
5 \\
6 \\
7 \\
8 \\
9 \\
10 \\
11 \\
12 \\
13 \\
14 \\
15 \\
16 \\
17 \\
18 \\
19 \\
20 \\
21\end{array}$ & $\begin{array}{r}0.700 \\
0.900 \\
4.600 \\
1.600 \\
1 \cdot 100 \\
1.790 \\
0.710 \\
0.700 \\
0.500 \\
0.300 \\
3.300 \\
25.600 \\
5.700 \\
111.800 \\
0.900 \\
0.800 \\
5.000 \\
19.900 \\
32.300 \\
13.600 \\
1.000\end{array}$ & $\begin{array}{r}0.230 \\
6 \cdot 130 \\
1 \cdot 580 \\
0 \cdot 140 \\
6.540 \\
1 \cdot 630 \\
0.310 \\
0.670 \\
0.260 \\
0.800 \\
7 \cdot 230 \\
60.690 \\
6.860 \\
35.600 \\
2.070 \\
6.300 \\
2.700 \\
16.100 \\
106.650 \\
49 \cdot 100 \\
0.510\end{array}$ & $\begin{array}{r}7 \cdot 63 \\
38 \cdot 93 \\
22 \cdot 11 \\
1.04 \\
108 \cdot 90 \\
12 \cdot 82 \\
4 \cdot 41 \\
8 \cdot 65 \\
2.38 \\
9 \cdot 17 \\
149 \cdot 56 \\
1213 \cdot 70 \\
83 \cdot 90 \\
225 \cdot 80 \\
64 \cdot 32 \\
118 \cdot 66 \\
54 \cdot 89 \\
242.00 \\
2133.00 \\
646 \cdot 25 \\
10 \cdot 24\end{array}$ & $\begin{array}{r}10 \cdot 21 \\
116 \cdot 80 \\
22 \cdot 30 \\
2 \cdot 50 \\
116 \cdot 62 \\
23 \cdot 10 \\
6 \cdot 40 \\
21 \cdot 10 \\
3 \cdot 50 \\
12 \cdot 90 \\
180 \cdot 10 \\
1213 \cdot 70 \\
83 \cdot 90 \\
277 \cdot 60 \\
68 \cdot 80 \\
176 \cdot 12 \\
74 \cdot 10 \\
271 \cdot 64 \\
2133 \cdot 00 \\
717 \cdot 40 \\
853 \cdot 10\end{array}$ \\
\hline
\end{tabular}

*Fibre numbers expressed as millions/g of dried tissue.

Table 2 Asbestos and other fibrous particle counts obtained from lung tissue specimens containing amosite as predominant asbestos mineral*

\begin{tabular}{|c|c|c|c|c|}
\hline $\begin{array}{l}\text { Specimen } \\
\text { No }\end{array}$ & $\begin{array}{l}\text { Optical microscope counts } \\
\times 10^{6}\end{array}$ & $\begin{array}{l}\text { Electron microscopic adjusted } \\
\text { counts } \times 10^{6}\end{array}$ & $\begin{array}{l}\text { Total electron microscopic } \\
\text { asbestos fibre counts } \times 10^{6}\end{array}$ & $\begin{array}{l}\text { Total electron } \\
\text { microscopic mineral } \\
\text { fibre counts } \times 10^{6}\end{array}$ \\
\hline $\begin{array}{l}22 \\
23 \\
24 \\
25 \\
26 \\
27 \\
28 \\
29 \\
30 \\
31 \\
32 \\
33 \\
34 \\
35 \\
36 \\
37 \\
38 \\
39 \\
40 \\
41 \\
42 \\
43\end{array}$ & $\begin{array}{r}0 \cdot 100 \\
7 \cdot 300 \\
10 \cdot 700 \\
0 \cdot 700 \\
6 \cdot 100 \\
4 \cdot 600 \\
1 \cdot 400 \\
1 \cdot 100 \\
5 \cdot 600 \\
0 \cdot 100 \\
1 \cdot 300 \\
1 \cdot 200 \\
0 \cdot 800 \\
0 \cdot 600 \\
19 \cdot 100 \\
0 \cdot 700 \\
116 \cdot 700 \\
0 \cdot 300 \\
8 \cdot 160 \\
1 \cdot 780 \\
3 \cdot 740 \\
34 \cdot 600\end{array}$ & $\begin{array}{r}1 \cdot 530 \\
22.750 \\
45 \cdot 500 \\
2.400 \\
2.070 \\
2.490 \\
1.490 \\
0.450 \\
5 \cdot 200 \\
0.470 \\
1 \cdot 170 \\
0.600 \\
1.790 \\
60.800 \\
102.980 \\
0.660 \\
76.200 \\
0.360 \\
22.750 \\
2.070 \\
2.490 \\
102.980\end{array}$ & 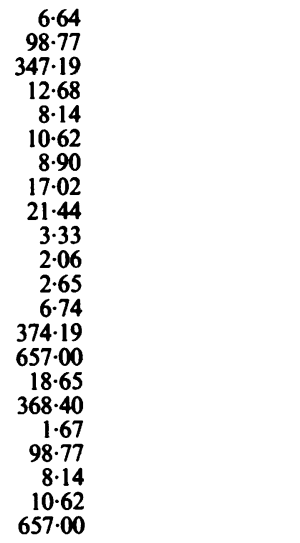 & $\begin{array}{r}25 \cdot 80 \\
99 \cdot 70 \\
347 \cdot 19 \\
15 \cdot 10 \\
8 \cdot 60 \\
10 \cdot 80 \\
12 \cdot 10 \\
18 \cdot 43 \\
1197 \cdot 44 \\
9 \cdot 38 \\
3 \cdot 00 \\
6 \cdot 91 \\
99 \cdot 10 \\
416 \cdot 64 \\
759 \cdot 80 \\
58 \cdot 90 \\
368 \cdot 40 \\
4 \cdot 90 \\
99 \cdot 70 \\
8 \cdot 60 \\
10 \cdot 80 \\
759 \cdot 80\end{array}$ \\
\hline
\end{tabular}

*Fibre numbers expressed as millions/g of dried tissue.

The results show that the total mineral fibre and also asbestos fibre obtained by electron microscopy were very much higher than those obtained by optical microscopic counting. The reason for this large difference was due to the fact that in the electron microscope the fibres of all sizes can be detected and counted while the optical counts represent only those fibres which can be resolved by the light microscope. The most critical dimension of asbestos fibres in determining whether or not they are observed in the optical microscope is their diameter. If a working resolution of $0.3 \mu \mathrm{m}$ is assumed for the optical microscope used in this study then all the fibres with diameters below this figure would not be observed and counted.

From the cumulative fibre diameter distributions of the various asbestos mineral fibres obtained from the electron microscopic examination of the tissue samples only $5 \%$ of the crocidolite, $26.5 \%$ of the amosite, and $0.14 \%$ of the chrysotile fibres were visible using 
Table 3 Asbestos and other fibrous particle counts obtained from lung tissue specimens containing chrysotile as predominant asbestos mineral*

\begin{tabular}{|c|c|c|c|c|}
\hline $\begin{array}{l}\text { Specimen } \\
\text { No }\end{array}$ & $\begin{array}{l}\text { Optical microscope counts } \\
\times 10^{6}\end{array}$ & $\begin{array}{l}\text { Electron microscopic adjusted } \\
\text { counts } \times 10^{6}\end{array}$ & $\begin{array}{l}\text { Total electron microscopic } \\
\text { asbestos fibre counts } \times 10^{6}\end{array}$ & $\begin{array}{l}\text { Total electron } \\
\text { microscopic mineral } \\
\text { fibre counts } \times 10^{6}\end{array}$ \\
\hline $\begin{array}{l}44 \\
45 \\
46 \\
47 \\
48 \\
49 \\
50 \\
51 \\
52 \\
53 \\
54 \\
55 \\
56 \\
57 \\
58 \\
59\end{array}$ & $\begin{array}{r}15 \cdot 500 \\
1 \cdot 240 \\
5 \cdot 600 \\
0 \cdot 150 \\
7.600 \\
0.310 \\
2.600 \\
7 \cdot 930 \\
0 \cdot 180 \\
9 \cdot 800 \\
0 \cdot 150 \\
7.600 \\
0.680 \\
0.830 \\
0.440 \\
3.200\end{array}$ & $\begin{array}{l}0.450 \\
2.118 \\
1.170 \\
0.560 \\
0.153 \\
0.140 \\
0.075 \\
0.258 \\
0.403 \\
0.120 \\
0.901 \\
0.120 \\
2.669 \\
0.077 \\
0.036 \\
0.400\end{array}$ & $\begin{array}{r}5 \cdot 1 \\
23 \cdot 15 \\
43.49 \\
16 \cdot 31 \\
3.93 \\
1 \cdot 08 \\
22 \cdot 00 \\
25 \cdot 63 \\
3 \cdot 85 \\
57 \cdot 59 \\
15 \cdot 14 \\
51.94 \\
25 \cdot 89 \\
3 \cdot 24 \\
7.06 \\
41 \cdot 31\end{array}$ & $\begin{array}{c}7 \cdot 9 \\
30 \cdot 4 \\
44 \cdot 20 \\
16 \cdot 31 \\
15 \cdot 59 \\
83 \cdot 58 \\
24 \cdot 51 \\
30 \cdot 41 \\
42 \cdot 51 \\
57 \cdot 59 \\
51 \cdot 10 \\
81 \cdot 19 \\
56 \cdot 09 \\
7 \cdot 59 \\
71 \cdot 19 \\
48.87\end{array}$ \\
\hline
\end{tabular}

*Fibre numbers expressed as millions/g of dried tissue.

an optical microscope. The total electron microscope asbestos fibre counts were therefore adjusted to remove that proportion of the fibre considered to be below the resolution of the optical microscope, and an adjusted electron microscopic asbestos count was obtained. The figures of optical and adjusted electron microscopic counts were fairly compatible (Tables 1 and 2). Table 3 shows that the agreement was not as good for the results as those obtained in Tables 1 and 2. The Figure gives a graphical representation of the optical and adjusted electron microscopic counts, in which the counts from the three Tables are represented by different symbols.

The Figure shows that the largest difference between the optical and electron microscopic counts was obtained as adjusted electron microscopic counts below $0.5 \mathrm{million} / \mathrm{g}$ of dried tissue, while the correlation at higher fibre counts was much better. It was those counts obtained from specimens, in which chrysotile was the predominant asbestos mineral, that deviated most from the ideal.

The correlation between the logarithms of the counts contained in the Figure is $0.56(p<0.001)$ which is significant. A similar correlation of the results from the specimens containing crocidolite, amosite, and chrysotile individually produced correlation coefficients of $0.79,0.74$, and 0.15 . The optical results were therefore more accurately predicted from the electron microscope when either crocidolite or amosite was predominant in the tissue specimens. The reason for the larger discrepancy of the results from those cases with mainly chrysotile present is not clear but it may be due to the fact that ferruginous bodies were included in the optical count as representing an asbestos fibre and that such bodies are propor-

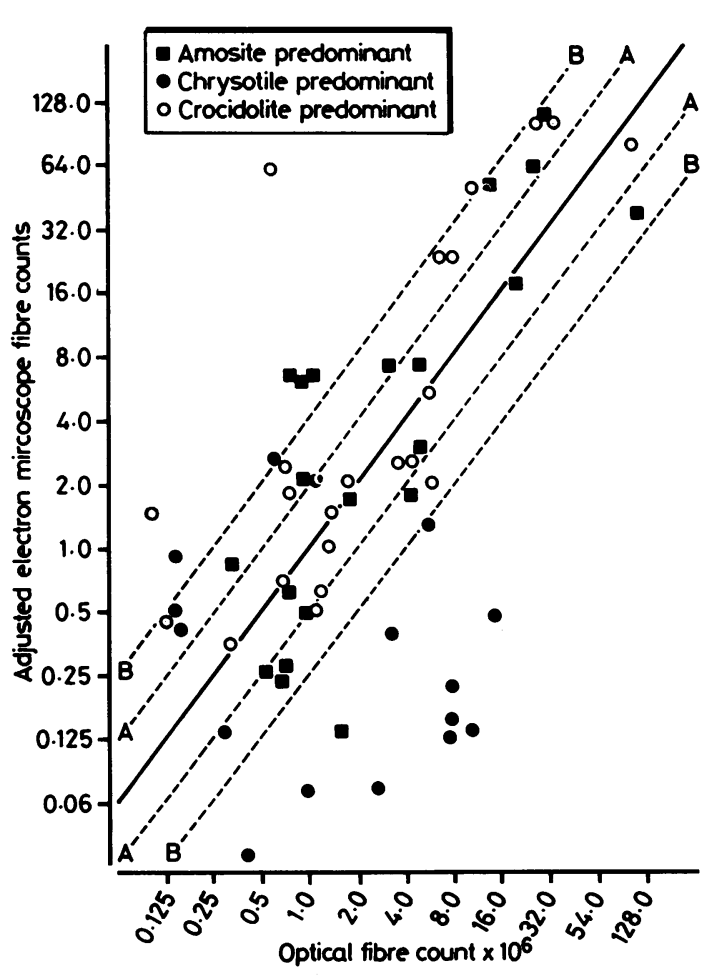

Figure Solid line represents line on which all points would lie if they were to be perfectly correlated. Pairs of dotted lines labelled $A$ and $B$ either side of the solid line represent limits of position of points if electron and optical counts were to differ by factors of 2 and 4, respectively. About $70 \%$ of the results are contained within a range of difference of 4 , while $30 \%$ are contained within a range of difference of 2 . 
Table 4 Fibres and ferruginous bodies detected (g/dried tissue)

\begin{tabular}{lclr}
\hline $\begin{array}{l}\text { Specimen } \\
\text { No }\end{array}$ & $\begin{array}{l}\text { Fibres detected } \\
\times 10^{6}\end{array}$ & $\begin{array}{l}\text { Ferruginous bodies } \\
\text { detected } \times 10^{6}\end{array}$ & Total \\
\hline 13 & 4.48 & 1.22 & 5.70 \\
19 & 50.45 & $8 \cdot 86$ & $59 \cdot 31$ \\
26 & 8.51 & 4.43 & 12.94 \\
36 & 28.01 & 6.38 & 34.39 \\
50 & 5.86 & 3.45 & $9 \cdot 31$ \\
55 & 2.61 & 5.06 & 7.67 \\
\hline
\end{tabular}

tionally present in much larger numbers in specimens where the fibre count is low. This point is well illustrated by the results contained in Table 4 . These were obtained from the optical recount of six of the specimens in which numbers of bodies and fibres observed were assessed independently and their totals noted.

When the optical fibre count was low the number of ferruginous bodies detected was relatively large and even exceeded the number of fibres observed in one case (Table 4). The difference, however, between the fibre and ferruginous body count increased as the number of fibres observed increased. The inclusion of body count with fibres to produce a total optical count of suspected asbestos fibre probably does contribute to the deviation of the optical results from those predicted by electron microscopy.

In the examination of the data obtained by both optical and electron microscopy no attempt has been made to assess the contribution of the non-asbestos mineral fibre to the optical count. It is almost certain, however, that some of the fibres observed using the optical microscope were non-asbestos mineral fibres.

\section{Discussion}

It is possible to predict from electron microscopic examination of a lung tissue sample the approximate concentration of fibres that would be assessed from an optical examination of tissue from the same lung. It is impossible, however, to make the reverse prediction, because it is not feasible to determine the proportion of the various asbestos mineral fibre types present in the sample using an optical microscope. The light microscope cannot be used to obtain an accurate assessment of the amount of asbestos fibre in lung tissue. As fibres are not identifiable using light microscopy the presence of non-asbestos fibres may seriously affect the integrity of any count made. Any authors reporting data using the light microscope should, therefore, be careful not to assume that all the fibres they observe are asbestos. The ratio of ferruginous bodies to fibres in tissue samples varies considerably, and the use of such objects in the assessment of an asbestos fibre count in tissue may be very misleading.

Considering the different tissue samples and prepa- ration techniques that were used in this study it is encouraging that the electron microscopic results were able to predict the optical fibre count so well. This is an indication that electron microscopic techniques assess the amount of asbestos mineral fibre in lung tissue fairly accurately.

Although the numbers of asbestos fibres detected in the lung tissue specimens are quoted in millions/g of dried tissue, (Tables 1-3) it must be remembered that because of their size these large fibre numbers represent only very small mass quantities of material. Rough estimates of fibre number and mass for the various types of asbestos show that $1 \times 10^{6}$ fibres of amosite detected by the electron microscope represents in the region of $10^{-6}$ of material while $1 \times 10^{6}$ fibres of chrysotile, because of its finer size is equivalent to less than $10^{-7} \mathrm{~g}$ of material. The mass of $1 \times$ $10^{6}$ fibres of crocidolite falls roughly midway between the mass figure for amosite and chrysotile respectively.

We thank Dr JSP Jones of the department of pathology, City Hospital, Nottingham for his encouragement and critical review of this paper and the British Medical Research Council and the MRC Pneumoconiosis Unit, Penarth for their financial and scientific collaboration.

\section{References}

${ }^{1}$ Gilson JC. Asbestos cancer: past and future hazards. Proc $R$ Soc Lond 1973;66:395.

${ }^{2}$ Langer AM, Pooley FD. Identification of single asbestos fibres in human tissues. Biological effects of asbestos. Lyon: International Agency for Research on Cancer, 1973:119-25.

${ }^{3}$ Pooley FD. The identification of asbestos dust with an electron microscope microprobe analyser. Annals of Occupational Hygiene 1975;18:181-6.

${ }^{4}$ Pooley FD. The use of an analytical electron microscope in the analysis of mineral dusts. Philos Trans $R$ Soc Lond (A) 1977;286:625-38.

${ }^{5}$ Pooley FD, Clark NJ. Quantitative assessment of inorganic fibrous particulates in dust samples with an analytical transmission electron microscope. Annals of Occupational Hygiene 1979;22:253-71.

${ }^{6}$ Oldham PD. Asbestos in lung tissue. In: Biological effects of asbestos. Bogovski P, ed. Lyon: International Agency for Research on Cancer, 1973:231.

${ }^{7}$ Whitwell F, Scott J, Grimshaw M. Relationship between occupations and asbestos-fibre content of the lungs in patients with pleural mesothelioma, lung cancer and other diseases. Thorax 1977;32:377.

${ }^{8}$ Martischneg KM, Newell DJ, Barnsley WC, Cowan WK, Feinmann EL, Oliver E. Unsuspected exposure to asbestos and bronchogenic carcinoma. Br Med J 1977;i:746-9.

${ }^{9}$ Morgan A, Holmes A. Concentrations and dimensions of coated and uncoated asbestos fibres in the human lung. Br J Ind Med 1980;37:25-32.

${ }^{10}$ Ashcroft T, Hepplestone AG. The optical and electron microscopic determination of pulmonary asbestos fibre concentration and its relation to the human pathological reaction. $J$ Clin Pathol 1973;26:224.

Requests for reprints to: Dr DL Ranson, Department of Pathology, University of Bristol, Bristol, England. 